****PREPRINT: Article accepted 11 April 2012 for publication in Psycho-Oncology****

\title{
A Feasibility Study of Group Cognitive Rehabilitation for Cancer Survivors: Enhancing Cognitive Function and Quality of Life
}

\author{
Alana Schuurs \& Heather J. Green \\ Behavioural Basis of Health Program, \\ Griffith Health Institute \& School of Applied Psychology \\ Griffith University \\ Gold Coast, Australia
}

\section{Correspondence to:}

Dr. Heather Green, School of Applied Psychology, Gold Coast campus, Griffith University, QLD, 4222, Australia

Ph: +61(0)7 55529086

Fax: +61(0)7 55528291

E-mail: h.green@griffith.edu.au

Acknowledgements: This research was funded through Griffith University Research Grant GURG36603 and the Psycho-Oncology Cooperative Research Group (PoCoG) Protocol Development Workshop 2007. PoCoG is jointly funded by Cancer Australia and the Cancer Institute NSW. This paper is based on a Doctor of Psychology (Clinical) dissertation by Alana Schuurs. We would like to thank A/Prof Bettina Meiser for assistance with protocol development; Dr Tamara Ownsworth for assistance with developing the intervention and associated treatment manuals; Elizma Piffero, Melissa Cheras, Kerrie Woods, Leah PischekSimpson, Louise Kelso, Phillip Law, Brooke Mitchell, Jacinta McKay, Lauren Baker, and Chrystal Gray for assistance with data collection; and Prof David Shum for his helpful feedback on an earlier draft of this paper. There were no financial or other conflicts of interest pertaining to this research. 


\begin{abstract}
Objective: This research aimed to address the gap in evidence-based treatment available for cancer survivors who are experiencing cognitive dysfunction through piloting a novel treatment intervention. The overall research question was whether a group cognitive rehabilitation intervention would be feasible for improving cognitive function and quality of life for people who have completed cancer treatment.
\end{abstract}

Methods: Three groups of adults were recruited: an intervention group of 23 cancer survivors who completed a 4-week group cognitive rehabilitation treatment, a comparison group of 9 cancer survivors, and a community sample of 23 adults who had never experienced cancer. Measures of objective and subjective cognitive function, quality of life, psychosocial distress and illness perceptions were used. The research design was non-randomised.

Results: The results indicated that the intervention was effective in improving overall cognitive function, visuospatial/constructional performance, immediate memory, and delayed memory beyond practice effects alone. It was helpful in reducing participants' perceptions of cognitive impairment and psychosocial distress, as well as promoting social functioning and understanding of cognition. The improvements were maintained at three months after the intervention. Participants reported a high level of satisfaction with the treatment.

Conclusions: The results provided evidence for the feasibility of a brief group-based cognitive rehabilitation intervention to treat cognitive problems experienced by cancer survivors.

Keywords: cancer; oncology; survivorship; cognitive dysfunction; cognitive-behavioural treatment 


\section{A Feasibility Study of Group Cognitive Rehabilitation for Cancer Survivors: Enhancing Cognitive Function and Quality of Life}

A cancer survivorship issue that is gaining in recognition is cognitive impairment [1]. Cognitive dysfunction has been associated with not only central nervous system (CNS) tumours and their treatments, but also with many other types of cancer and treatment [1-4]. Treatments as diverse as chemotherapy, radiotherapy, hormonal treatments, bioimmunotherapy, and adjunctive medications, as well as the cancer itself before treatment, have been associated with cognitive changes [4-7].

Conceptual reviews have modelled the complex mix of factors associated with cognitive dysfunction, including demographic, tumour, treatment, and psychosocial variables [6,8]. Additional complexity arises from a distinction between objective and subjective findings. A recent review of cognitive effects of chemotherapy reported objective impairments in $15-50 \%$ of patients [3]. Self-report incidence rates as high as $71 \%$ at six months post-chemotherapy have been found [9]. Frequently, there is no correlation between objective and subjective cognition [6,10]. However, while this discrepancy is widely acknowledged, there remains a need for evidence-based interventions to address this survivorship issue [1,5]. Cognitive rehabilitation has the potential to address both subjective and objective cognitive difficulties [11].

Very few published studies have examined whether cognitive rehabilitation can affect cognitive dysfunction following adult-onset non-CNS tumours [12-15]. Brief individual cognitive rehabilitation for breast cancer survivors, comprising four face-to-face sessions plus phone calls and a workbook, showed improved self-reported cognition, quality of life, and objective cognition in 29 participants [12]. A randomised study of the same intervention showed improved spiritual quality of life and verbal memory compared to waitlist controls [13]. Computerised rehabilitation has also shown promise [14], as has group cognitive rehabilitation among cancer survivor participants in a general cognitive rehabilitation program for older adults [15].

In addition to cognitive difficulties, issues such as quality of life and mental health are significant concerns for many cancer survivors [3]. A key model of individual differences in these adjustment domains is the Self-Regulatory model of illness perceptions [16]. Only recently applied to cancer survivorship, the Self-Regulatory Model describes how individuals mentally represent illness and how these representations may influence treatment outcomes [16]. Previous illness perceptions research has suggested that cancer patients and survivors 
who show low illness coherence (limited understanding of their condition), low treatment control and who view their cancer as being chronic, uncontrollable, having high consequences and serious symptoms also show poorer outcomes in physical and mental health, especially when subjective outcomes are considered [17,18]. From this research, it can be predicted that illness perceptions would associate with subjective cognition but this has not been tested in relation to cancer.

The present study addressed the gap in evidence-based treatment for cancer survivors who experience cognitive dysfunction through developing and evaluating a new brief intervention incorporating cognitive rehabilitation principles. This intervention was novel in using group rather than individual treatment, and included cancer survivors who represented a mix of cancer diagnoses and treatments, rather than focussing on a single tumour or treatment history. Further to this, the study aimed to offer additional insight into the complex relationships between objective and subjective cognitive dysfunction, quality of life and mental health, as well as explore the role of illness perceptions in cognitive dysfunction for the first time.

\section{Methods}

\section{Participants}

Intervention participants were 23 cancer survivors aged 34-84 years $(M=58.2$, $S D=11.8$ ). A cancer comparison group comprised 9 survivors (age $M=58.3, S D=8.6$ ) who were waitlisted but declined to attend the intervention $(n=3)$, or volunteered after the final group began ( $n=6)$. Referral rates were not sufficient to allow randomised group allocation. A community comparison group comprised 23 adults with no history of cancer (age $M=58.5$, $S D=11.1)$. Demographic and medical characteristics are summarised in Table 1.

Insert Table 1 about here

All participants were aged at least 18 years and fluent in English. Additional criteria for cancer survivors were previous diagnosis of adult-onset cancer and completion of major treatments such as surgery, chemotherapy, and radiotherapy at least six months prior. One intervention participant was four months post- treatment but was included on ethical and compassionate grounds. Exclusion criteria were childhood cancer history, known primary or secondary CNS tumour, and history of intracranial radiotherapy or intrathecal chemotherapy.

After ethical approval, participants were recruited through flyers at university and community locations, as well as cancer support organisations and a public hospital (cancer survivors) and personal contacts of the research team (community comparison). Community 
participants were recruited for a parallel psychometric study with 72 participants aged 20-79 years [19]; 23 individuals who matched intervention participants for age, gender and education were selected to form the community comparison group for the present study. Measures

Objective Cognitive Function. The Repeatable Battery for Assessment of Neuropsychological Status (RBANS) has demonstrated high internal reliability, test-retest stability, and divergent and convergent validity [20]. The second objective measure, the Trail Making Test (TMT), assesses complex visual attention and psychomotor speed with sensitivity and validity [21] and has high test-retest reliability [22]. Both measures have demonstrated sensitivity to cognitive rehabilitation [12,23].

Subjective Cognitive Function. The authors of the 38-item Multiple Ability SelfReport Questionnaire (MASQ) found excellent internal reliability, test-retest reliability, and criterion, concurrent and discriminant validity [24]. The MASQ was sensitive to cognitive rehabilitation in cancer survivors [12]. The 37-item Functional Assessment of Cancer Therapy - Cognitive Scale (FACT-Cog v3) was used as a subjective cognition measure developed for cancer survivors [25]; the similar FACT-Cog v2 has demonstrated reliability and validity [26].

Adjustment and Illness Perceptions. The 30-item European Organisation for Research and Treatment of Cancer Core Quality of Life Questionnaire (EORTC-QLQC30v3; [27]) measures multiple adjustment domains. Its functioning and global quality of life scale show high internal consistency (Cronbach's alpha>.82, except cognitive functioning alpha=.55 [28]). The 10-item Kessler Psychological Distress Scale (K10) measures psychosocial distress, with excellent internal consistency, sensitivity and specificity [29]. The 9-item Brief Illness Perception Questionnaire (BIPQ) has shown good test-retest reliability as well as concurrent and discriminant validity [30].

Participant Satisfaction. Three 5-point items were used: satisfaction with treatment (1=strongly dissatisfied to 5=strongly satisfied); extent of change in cognitive problems $(1=$ got a lot worse to $5=$ improved a lot $)$; and likelihood of recommending the program if a friend had similar problems ( $1=$ very unlikely to $5=$ very likely). An overall program rating between $1=$ very poor to $10=$ excellent was also requested. Demographic and participant satisfaction items are available from the corresponding author. 


\section{Intervention}

The intervention developed for this study was based on self-regulatory cognitive rehabilitation [11,31] and cognitive behavioural principles [32,33] and was manualised [34,35]. The authors co-facilitated the weekly 2-hour group sessions and between-session homework. Each session first focussed on psychoeducation, followed by a thematic group discussion and a 10-15 minute refreshment break. The second half of each session emphasised developing and applying skills.

Session One (Aging, health, cancer and cognitive function) involved psychoeducation on cognition, and training in goal setting, problem solving and relaxation. Sessions Two (Memory) and Three (Attention) involved education and skills training regarding memory and attention respectively, including compensatory and enhancement strategies [11]. Session Four (Fatigue, emotions and cognition) involved psychoeducation and cognitive-behavioural strategies related to emotional adjustment, fatigue, sleep, and self-care. Four groups of 4-8 participants completed the intervention at no charge.

\section{Procedure}

Participants completed assessments at baseline (T1), post-treatment (T2, 6 weeks after T1) and follow-up (T3, 3 months after T2, for intervention participants). Between T1 and T2, intervention participants completed the group program, and comparison participants completed no intervention. Assessors were trained and supervised by the second author (a registered clinical health psychologist). The nine assessors were psychology graduates in postgraduate or advanced undergraduate studies and were not involved in delivering the intervention. On eight occasions, the first author completed assessments as other assessors were not available.

\section{Statistical Analyses}

Group(3) x Time(2) ANOVAs were computed. When statistical assumptions for ANOVA were not met, the non-parametric Kruskal-Wallis and Wilcoxon Signed-Rank tests were used. Simple effects tests used familywise Bonferroni corrections for multiple planned comparisons. Effect sizes for interactions $(d)$ were computed using the pooled pre-test standard deviation for the two groups being compared [36]. Positive interaction effects represent intervention-group improvements that exceeded comparison-group improvements. Clinical significance of changes was calculated using Jacobson and Truax's Reliable Change Index formulae and community group values for pre-test standard deviation and test-retest reliability [37]. For the K10, a further indicator of clinical significance was whether participants moved into the non-distressed range [29,37]. Maintenance effects were assessed 
by comparing $\mathrm{T} 1$ and $\mathrm{T} 3$. The pattern of results was the same for both completer and intention-to-treat analyses, where the latter analyses estimated missing data as remaining unchanged from the previous assessment. Inferential statistics below used completer analyses.

\section{Results}

All intervention participants completed treatment. Missed sessions were compensated for by participants working through the manual and receiving briefings from facilitators: Ten participants missed one session (47.8\%) and 2 missed two sessions (8.7\%). T2 assessment data were missing for 2 participants (illness: one intervention participant; family bereavement: one cancer comparison). Three intervention participants had missing T3 data (illness: two participants; moved away: one participant).

\section{Objective Cognitive Function}

Means and standard deviations for objective and subjective cognitive measures are shown in Table 2. No RBANS measure showed a main effect for group. All RBANS measures except immediate memory had a main effect of time, indicating improved performance at retest. For RBANS total, there was a significant Group x Time interaction, $F(2,50)=19.26, p<.001$. The interaction occurred because the intervention group significantly improved in overall cognitive function, $p<.001$ but comparison groups did not (see Figure 1 and Table 2). Similarly, statistically significant Group x Time interactions were found for the RBANS subscales of immediate memory, visuospatial/constructional, and delayed memory. See Table 2 for effect sizes of intervention group changes corrected for comparison group changes [36]. For RBANS total, eight intervention participants met reliable change criteria (36.4\% [25]). One cancer comparison participant showed reliable improvement (12.5\%). No community comparison participant improved reliably.

Insert Table 2 about here

Insert Figure 1 about here

For the TMT, a main effect of Time indicated faster Trails A performance at T2 than $\mathrm{T} 1, Z(52)=-2.76, p=.006$. A similar trend was seen for improved Trails B performance at T2 but this did not reach two-tailed significance, $Z(52)=-1.675, p=.094$. There was no Group effect for Trails A or B. 


\section{Subjective Cognitive Function}

For the MASQ, there were no main effects and no interaction. Unexpectedly, community participants reported improved subjective function at retest. For the FACT-Cog, interaction effects were not significant, although the power to detect these interactions was low. There was a main effect of group on all four FACT-Cog subscales, with cancer comparison participants reporting better cognitive performance than intervention participants, $p=.007-.042$. There was also a main effect of time indicating improvement in perceived cognitive impairment at re-test, $F(1,16)=10.29, p=.005$. On the FACT-Cog perceived cognitive impairments score, three intervention participants (30.0\%) and one cancer comparison participant $(12.5 \%)$ met reliable change criteria.

\section{Quality of Life, Emotional Distress and Illness Perceptions}

Table 3 shows relevant descriptive statistics. There were no main effects of time for EORTC-QLQ-C30 quality of life measures. However, significant group effects occurred for role, emotional, and cognitive function at $\mathrm{T} 1\left(\chi^{2}(2)=7.63-11.57, \mathrm{p}=.003-.022\right)$ and $\mathrm{T} 2$ $\left(\chi^{2}(2)=6.42-14.62, p=.001-.040\right)$, due to lower quality of life reported by intervention than community participants. There was also a group effect for social function at $\mathrm{T} 1\left(\chi^{2}(2)=10.70\right.$, $\mathrm{p}=.005)$, but not $\mathrm{T} 2\left(\chi^{2}(2)=0.62, \mathrm{p}=.735\right.$.) The intervention group significantly improved in social functioning by $\mathrm{T} 2, Z(20)=2.56, p=.010$.

\section{Insert Table 3 about here}

For psychosocial distress (K10), there was no interaction and no main effect of time. There was a significant group effect at $\mathrm{T} 1\left(\chi^{2}(2)=15.01, \mathrm{p}=.001\right)$ and $\mathrm{T} 2\left(\chi^{2}(2)=10.27\right.$, $\mathrm{p}=.006$ ), due to greater distress among intervention participants than comparison participants. However, among intervention participants who were clinically distressed at pre-treatment, psychosocial distress significantly reduced at post-treatment, $Z(6)=-2.03, \mathrm{p}=.043$. As a significant K10 time effect was only noted for participants whose scores started in the clinical range, only those participants from each group were considered for reliable change. Three intervention participants (42.9\%) and one community comparison participant (33.3\%) demonstrated reliable change.

For illness perceptions (BIPQ), no interactions were found. A main effect of time was noted for illness coherence, $F(1,49)=6.73, p=.012$. Simple effects tests showed that intervention participants improved significantly in illness coherence after treatment, $p=.003$, whereas comparison participants did not, $\mathrm{p}=.274-.517$. When clinical significance was 
considered for illness coherence, one participant in each group met reliable change criteria (intervention $4.5 \%$, cancer comparison $12.5 \%$, community $4.3 \%$ ).

\section{Maintenance at Followup}

As shown in Tables 2 and 3, almost all significant gains by intervention participants at T2 were maintained at T3. Maintenance was demonstrated for RBANS total (T2 withingroup effect size $d=1.37$; T3 $d=1.42$ ), Immediate Memory (T2=0.55;T3=0.74), Visuospatial/Constructional $(\mathrm{T} 2=1.44, \mathrm{~T} 3=1.69)$, and Delayed Memory $(\mathrm{T} 2=1.50 ; \mathrm{T} 3=1.81)$. Subjective cognition demonstrated maintenance effects for FACT-Cog perceived cognitive impairment $(\mathrm{T} 2=0.45 ; \mathrm{T} 3=0.50)$ and perceived cognitive abilities $(\mathrm{T} 2=0.55 ; \mathrm{T} 3=0.57)$. Other self-report measures demonstrated maintenance of improved social function (T2 $=0.42 ; \mathrm{T} 3=0.31)$, psychosocial distress for participants who started in the clinical range $(\mathrm{T} 2=1.55 ; \mathrm{T} 3=1.37)$, and illness coherence $(\mathrm{T} 2=0.63 ; \mathrm{T} 3=0.83)$.

No maintenance of T2 gains in RBANS Language and Attention/Concentration was found; these variables also contrasted with other RBANS measures in that they did not show Group x Time interactions. One variable, Trails A, improved significantly at T3, $Z(19)=-3.47$, $p=.001$, but not $\mathrm{T} 2(\mathrm{~T} 2=0.09 ; \mathrm{T} 3=0.28)$.

\section{Participant Satisfaction}

At post-treatment, all 21 intervention participants who provided feedback reported being satisfied or very satisfied. Cognitive difficulties were rated improved a lot by $2 / 21$ participants, improved a little by 17 , and no change by 2 . Twenty participants indicated that they would be likely or very likely to recommend the group to a friend, with one neutral response. When asked to rate the group overall, 15/21 participants rated the program as excellent and 6 as good. Similar feedback was received at follow-up: 5/18 participants now thought their cognitive difficulties had improved a lot, 8 improved a little, 4 no change, and one reported that their cognitive difficulties had got a little worse.

\section{Discussion}

The main aim was to determine the feasibility of brief group cognitive rehabilitation for cancer survivors. The intervention was associated with improved objective and subjective cognition, psychosocial distress, social functioning, and perceived understanding of cognition that exceeded changes in comparison groups. Gains were maintained at three month followup. The intervention was acceptable and feasible to run. This represents a positive step forward in addressing the need for interventions for cancer survivors with cognitive difficulties [38]. 
Intervention participants' gains in overall cognitive performance, visuospatial/constructional performance, immediate memory, and delayed memory showed within-group effect sizes that compared favourably to previous cognitive rehabilitation studies [12,23]. After accounting for comparison group changes, intervention participants' objective improvements exceeded recent recommendations that an effect size of $d=0.41$ be considered as a "recommended minimum practical effect", 1.15 a "moderate" and 2.70 a "strong" effect in social sciences [39]. The three groups did not differ in baseline objective cognition, except that visuospatial/constructional performance was significantly higher among community comparison than cancer survivor participants.

At baseline, intervention participants reported significantly worse FACT-Cog3 subjective cognition than cancer comparison participants and were more likely to report adapting their behaviour due to perceived cognitive changes, such as delaying return to work. This is consistent with previous research which has noted that individuals who decline participation in cancer support groups are often in a less distressed state [40]. Intervention participants improved significantly on two FACT-Cog3 subscales and no longer differed from cancer comparison participants on Perceived Cognitive Ability after the intervention. Thus, the FACT-Cog3 appeared to be more sensitive to both baseline subjective cognition and intervention gains than the MASQ. Given that the FACT-Cog3 was developed specifically for cancer survivors, it would seem to be a promising measure for further psychooncology research.

Intervention gains in other self-report measures were also consistent with distress reducing towards the baseline levels of the comparison groups. This pattern was seen for social functioning and for psychosocial distress among participants with clinical distress at pre-treatment. These effect sizes were comparable with previous research [12,41]. Improved social functioning may suggest a specific social benefit from group treatment. Perceived illness coherence demonstrated this same pattern compared to the cancer comparison group. Illness perceptions were actually significantly more dysfunctional for community participants (who were instructed to imagine what cognitive difficulties would be like for someone with these problems) than the cancer survivor groups (who were asked about "your cognitive difficulties").

A strength regarding generalisability came from the mix of genders, ages, cancer types and cancer treatments. A focus on breast cancer has limited much previous research regarding generalisation to other cancer types [3]. In the present study, reliable improvement on the main outcome measure (RBANS total) was seen for intervention participants with 
breast, colorectal, prostate, and testicular cancer. Examination of subgroups showed no trends for intervention response to associate with the type of tumour or treatment. Recruitment of participants from a range of sources suggested that the research had applicability to a number of organisations relevant to cancer survivors. Finally, an advantage was found in the high acceptability and low attrition rate of the intervention group (4.3\% post-intervention), compared to the $20 \%$ attrition rate that has been reported as typical for cancer survivor group interventions [42].

However, a number of limitations are noted. Sample sizes were relatively small, which limits statistical power to detect differences between groups, including the post-hoc analysis regarding which tumour types showed effects [43]. It is known that comparison of uneven group sizes is not methodologically ideal [43]. To address the issues of both small and uneven group numbers, interpretation of results incorporated effect sizes which are independent of group size [43], and comparisons of percentage of reliable change between groups [37].

Another limitation was non-random allocation to intervention and cancer comparison groups. A randomised controlled trial would provide a stronger test of efficacy now that feasibility has been established [3]. The finding that participants started and finished in a normal range for some measures, such as MASQ subjective cognition, was not considered typical for cancer survivors $[3,12]$ and suggests that baseline impairment would be an important inclusion criterion in future intervention studies. Ideally, all assessors would be blinded to group allocation, whereas $6 \%$ of assessments were conducted by one of the intervention facilitators. Finally, it was noted that the scope of the present study does not address the complete range of potential factors associated with cognitive impairment for cancer survivors $[6,8]$.

In conclusion, this research supported the practicality and acceptability of a brief group cognitive rehabilitation intervention for cancer survivors [34,35]. These results suggest that further research regarding brief group interventions for this population is warranted $[1,12,38]$. In addition, future research which incorporates illness perceptions would be beneficial as this remains an emerging area of research for cancer survivors $[17,18]$. 


\section{References}

1. Schagen SB, Vardy J, Steering Committee of the International Cognition and Cancer Task Force. Cognitive dysfunction in people with cancer. Lancet Oncol 2007;8:852-853, doi:10.1016/S1470-2045(07)70287-5.

2. Harder H, Van Gool AR, Duivenvoorden HJ, Cornelissen JJ, Eijkenboom WMH, Barge

ReMY, et al. Case-referent comparison of cognitive functions in patients receiving haematopoietic stem-cell transplantation for haematological malignancies: Two-year followup results. Eur J Cancer 2007;43:2052-2059, doi:10.1016/j.ejca.2007.06.005.

3. Vardy J, Tannock I. Cognitive function after chemotherapy in adults with solid tumours. Crit Rev Oncol Hematol 2007;63:183-202, doi:10.1016/j.critrevonc.2007.06.001.

4. Wefel JS, Kayl AE, Meyers CA. Neuropsychological dysfunction associated with cancer and cancer therapies: a conceptual review of an emerging target. Br J Cancer 2004;90:16911696, doi:10.1038/sj.bjc.6601772.

5. Ahles T, Saykin A, McDonald B, Furstenberg C, Cole B, Hanscom B, et al. Cognitive function in breast cancer patients prior to adjuvant treatment. Breast Cancer Res Treat 2008;110:143-152, doi:10.1007/s10549-007-9686-5.

6. Green HJ, Pakenham KI, Gardiner RA. Cognitive deficits associated with cancer: A model of subjective and objective outcomes. Psychol Health Med 2005;10:145-160, doi:10.1080/13548500500093308.

7. Vearncombe KJ, Rolfe M, Wright M, Pachana NA, Andrew B, Beadle G. Predictors of cognitive decline after chemotherapy in breast cancer patients. J Int Neuropsychol Soc 2009;15:951-962, doi:10.1017/s1355617709990567.

8. Hess LM, Insel KC. Chemotherapy-related change in cognitive function: a conceptual model. Oncol Nurs Forum 2007;34:981-994, doi:10.1188/07.ONF.981-994.

9. Shilling V, Jenkins V. Self-reported cognitive problems in women receiving adjuvant therapy for breast cancer. Eur J Oncol Nurs 2007;11:6-15, doi:10.1016/j.ejon.2006.02.005. 10. Poppelreuter M, Weis J, Kulz AK, Tucha O, Lange KW, Bartsch HH. Cognitive dysfunction and subjective complaints of cancer patients. a cross-sectional study in a cancer rehabilitation centre. Eur J Cancer 2004;40:43-49.

11. Wilson BA. Cognitive rehabilitation: How it is and how it might be. J Int Neuropsychol Soc 1997;3:487-496.

12. Ferguson RJ, Ahles TA, Saykin AJ, McDonald BC, Furstenberg CT, Cole BF, et al. Cognitive-behavioral management of chemotherapy-related cognitive change. Psycho-Oncol 2007;16:772-777, doi:10.1002/pon.1133.

13. Ferguson RJ, McDonald BC, Rocque MA, Furstenberg CT, Horrigan S, Ahles TA, et al. Development of CBT for chemotherapy-related cognitive change: results of a waitlist control trial. Psycho-Oncol 2012;21:176-186, doi:10.1002/pon.1878.

14. Kim S, Stasio C, Spina L, Tinker DE, Mahncke HW (2008). Effects on health-related quality of life in individuals with "chemobrain" using a brain-plasticity-based training program. Paper presented at the 36th Annual Meeting of the International Neuropsychological Society. Retrieved 10 April, 2012, from http://journals.cambridge.org/download.php?file=\%2FINS\%2FINS14_S1\%2FS13556177080

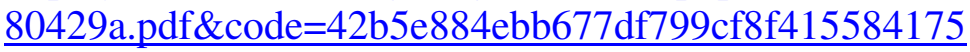

15. McDougall GJ, Becker H, Acee TW, Vaughan PW, Delville CL. Symptom management of affective and cognitive disturbance with a group of cancer survivors. Arch Psychiatr Nurs 2011;25:24-35, doi:10.1016/j.apnu.2010.05.004.

16. Leventhal H, Nerenz DR, Steele DJ. Illness perceptions and coping with health threat. In Handbook of psychology and health, Volume IV: social psychological aspects of health, Baum A, Taylor SE,Singer JE (Eds.). Hillsdale, NJ: Erlbaum, 1984;219-252. 
17. Rozema H, Vollink T, Lechner L. The role of illness representations in coping and health of patients treated for breast cancer. Psycho-Oncol 2009;18:849-857, doi:10.1002/pon.1488. 18. Traeger L, Penedo FJ, Gonzalez JS, Dahn JR, Lechner SC, Schneiderman N, et al. Illness perceptions and emotional well-being in men treated for localized prostate cancer. $J$ Psychosom Res 2009;67:389-397, doi:10.1016/j.jpsychores.2009.03.013.

19. Cheras MJ. Does the test-retest reliability of neuropsychological tests vary with age? Unpublished Honours thesis, Griffith University, Gold Coast, Australia, 2009.

20. Randolph C. Manual for the Repeatable Battery for the Assessment of Neuropsychological Status. San Antonio, TX: The Psychological Corporation, 1998. 21. Lezak MD. Neuropsychological assessment (3rd ed.). New York: Oxford University Press, 1995.

22. Dikmen SS, Heaton RK, Grant I, Temkin NR. Test-retest reliability and practice effects of Expanded Halstead-Reitan Neuropsychological Test Battery. J Int Neuropsychol Soc 1999;5:346-356.

23. Smith GE, Housen P, Yaffe K, Ruff R, Kennison RF, Mahncke HW, et al. A cognitive training program based on principles of brain plasticity: Results from the Improvement in Memory with Plasticity-based Adaptive Cognitive Training (IMPACT) study. J Am Geriatr Soc 2009;57:594-603, doi:10.1111/j.1532-5415.2008.02167.x.

24. Seidenberg M, Haltiner A, Taylor MA, Hermann BB, Wyler A. Development and validation of a Multiple Ability Self-Report Questionnaire. J Clin Exp Neuropsychol 1994;16:93-104, doi:10.1080/01688639408402620.

25. Wagner LI, Lai JS, Cella D, Sweet J, S F. Chemotherapy-related cognitive deficits: development of the FACT-Cog instrument. Ann Behav Med 2004;27:S10.

26. Lai JS, Butt Z, Wagner L, Sweet JJ, Beaumont JL, Vardy J, et al. Evaluating the dimensionality of perceived cognitive function. J Pain Symptom Manage 2009;37:982-995, doi:10.1016/j.jpainsymman.2008.07.012.

27. Aaronson NK, Ahmedzai S, Bergman B, Bullinger M, Cull A, Duez NJ, et al. The European Organization for Research and Treatment of Cancer QLQ-C30: A quality-of-life instrument for use in international clinical trials in oncology. J Natl Cancer Inst 1993;85:365376, doi:10.1093/jnci/85.5.365.

28. Michelson H, Bolund C, Nilsson B, Brandberg Y. Health-related quality of life measured by the EORTC QLQ-C30: Reference values from a large sample of the Swedish population. Acta Oncol 2000;39:477 - 484.

29. Kessler RC, Andrews G, Colpe LJ, Hiripi E, Mroczek DK, Normand S-LT, et al. Short screening scales to monitor population prevalences and trends in non-specific psychological distress. Psychol Med 2002;32:959-976, doi:10.1017/S0033291702006074.

30. Broadbent E, Petrie KJ, Main J, Weinman J. The Brief Illness Perception Questionnaire. J Psychosom Res 2006;60:631-637, doi:10.1016/j.jpsychores.2005.10.020.

31. Fleming JM, Ownsworth T. A review of awareness interventions in brain injury rehabilitation. Neuropsychol Rehabil 2006;16:474-500, doi:10.1080/09602010500505518. 32. Newell SA, Sanson-Fisher RW, Savolainen NJ. Systematic review of psychological therapies for cancer patients: overview and recommendations for future research. $J$ Natl Cancer Inst 2002;94:558-584.

33. Osborn RL, Demoncada AC, Feuerstein M. Psychosocial interventions for depression, anxiety, and quality of life in cancer survivors: meta-analyses. Int J Psychiatry Med 2006;36:13-34.

34. Schuurs A, Green HJ. Clinician's manual for "Responding to Cognitive Concerns"

(ReCog): A four-session cognitive rehabilitation program for adults recovering from cancer. Unpublished treatment manual. Gold Coast, Australia: Griffith University, 2009. 
35. Schuurs A, Green HJ. Participant's manual for "Responding to Cognitive Concerns" (ReCog): A four-session cognitive rehabilitation program for adults recovering from cancer. Unpublished treatment manual. Gold Coast, Australia: Griffith University, 2009.

36. Morris SB. Estimating effect sizes from pretest-posttest-control group designs. Organ Res Methods 2008;11:364-386, doi:10.1177/1094428106291059.

37. Jacobson NS, Truax P. Clinical significance: A statistical approach to defining meaningful change in psychotherapy research. J Consult Clin Psychol 1991;59:12-19, doi:10.1037/0022-006X.59.1.12.

38. Hurria A, Lachs M. Is cognitive dysfunction a complication of adjuvant chemotherapy in the older patient with breast cancer? Breast Cancer Res Treat 2007;103:259-268, doi:10.1007/s10549-006-9383-9.

39. Ferguson CJ. An effect size primer: A guide for clinicians and researchers. Prof Psychol: Res Pr 2009;40:532-538.

40. Cameron LD, Booth RJ, Schlatter M, Ziginskas D, Harman JE. Changes in emotion regulation and psychological adjustment following use of a group psychosocial support program for women recently diagnosed with breast cancer. Psycho-Oncol 2007;16:171-180, doi:10.1002/pon.1050.

41. Dolbeault S, Cayrou S, Brédart A, Viala AL, Desclaux B, Saltel P, et al. The effectiveness of a psycho-educational group after early-stage breast cancer treatment: results of a randomized French study. Psycho-Oncol 2009;18:647-656, doi:10.1002/pon.1440.

42. Gottlieb BH, Wachala ED. Cancer support groups: a critical review of empirical studies. Psycho-Oncol 2007;16:379-400, doi:10.1002/pon.1078.

43. Hair J, Tatham R, Anderson R, Black W. Multivariate Data Analysis (5th Edition). Upper Saddle River, NJ: Prentice Hall, 1998. 
Table 1

Participant Characteristics

\begin{tabular}{|c|c|c|c|}
\hline Variable & $\begin{array}{l}\text { Intervention } \\
\qquad(n=23)\end{array}$ & $\begin{array}{c}\text { Cancer } \\
\text { Comparison } \\
(n=9)\end{array}$ & $\begin{array}{c}\text { Community } \\
\text { Comparison } \\
(n=23)\end{array}$ \\
\hline & $M(S D)$ Range & $M(S D)$ Range & $M(S D)$ Range \\
\hline Age (years) & $58.2(11.8) \quad 34-84$ & $58.3(8.6) 47-74$ & 58.5 (11.1) 34-78 \\
\hline \multirow[t]{2}{*}{ Education (years) } & 15.4 (3.2) $10-20$ & 13.6 (3.4) 10-19 & $15.7 \quad$ (3.9) $9-25$ \\
\hline & Median (SD) Range & $\underline{\text { Median }(S D) \text { Range }}$ & Median (SD) Range \\
\hline $\begin{array}{l}\text { Months since cancer } \\
\text { diagnosis }\end{array}$ & 54.0 (44.8) 19-166 & 60.0 (41.7) 19-162 & - \\
\hline $\begin{array}{l}\text { Months since finished } \\
\text { cancer treatment }\end{array}$ & $36.0(32.8) \quad 4-123$ & 48.0 (44.6) 11-159 & - \\
\hline & $\underline{\%}$ & $\underline{\%}$ & $\underline{\%}$ \\
\hline Living with partner & 73.9 & $7 \overline{7.8}$ & $7 \overline{8.3}$ \\
\hline Female & 56.5 & 77.8 & 56.5 \\
\hline Born in Australia & 78.9 & 77.8 & 65.2 \\
\hline Neurological history & 4.3 & 0.0 & 0.0 \\
\hline \multicolumn{4}{|l|}{ Cancer type } \\
\hline Breast & 47.8 & 55.6 & - \\
\hline Prostate & 17.4 & 0.0 & - \\
\hline Colorectal & 17.4 & 33.3 & - \\
\hline Neck & 4.3 & 0.0 & - \\
\hline Testicular & 4.3 & 0.0 & - \\
\hline Ovarian & 0.0 & 11.1 & - \\
\hline Mixed & 8.7 & 0.0 & - \\
\hline \multicolumn{4}{|l|}{ Treatment } \\
\hline Chemotherapy & 73.9 & 44.4 & - \\
\hline Radiotherapy & 60.9 & 55.6 & - \\
\hline Surgery & 82.6 & 100.0 & - \\
\hline Other & 52.2 & 55.6 & - \\
\hline \multicolumn{4}{|l|}{ Cognitive difficulties } \\
\hline After cancer treatment & 82.6 & 88.9 & - \\
\hline Current difficulties & 65.2 & 66.7 & - \\
\hline Required adaptations ${ }^{\mathrm{b}}$ & 78.3 & $33.3^{\mathrm{a}}$ & - \\
\hline
\end{tabular}

${ }^{a}$ Significantly lower in cancer comparison than intervention group.

${ }^{\mathrm{b}}$ Examples: change work duties; delay return to work for cognitive reasons 
Table 2

Interaction Effects, Means (and Standard Deviations) for Cognitive Measures

\begin{tabular}{|c|c|c|c|c|c|c|c|c|c|}
\hline \multirow[t]{3}{*}{ Measure } & \multirow{3}{*}{\multicolumn{2}{|c|}{$\frac{\text { Interaction }}{\mathrm{d}_{\mathrm{I}-\mathrm{Can}} / \mathrm{d}_{\mathrm{I}-\mathrm{Com}}(p)}$}} & \multicolumn{3}{|c|}{ Time 1} & \multicolumn{3}{|c|}{ Time 2} & \multirow{3}{*}{$\begin{array}{c}\text { Time } 3 \\
\text { Intervention } \\
(n=20)\end{array}$} \\
\hline & & & Intervention & Cancer & Community & Intervention & Cancer & Community & \\
\hline & & & & Comparison & & & Comparison & 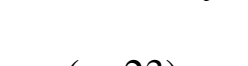 & \\
\hline \multicolumn{10}{|l|}{ Neuropsy. Battery (RBANS) } \\
\hline Total & $1.00 / 1.1$ & $(.000)$ & $95.1 \quad(9.9)$ & $94.6 \quad(8.2)$ & 101.3( & $108.7(11.0)^{* * *}$ & $98.4(11.5)$ & $100.7(13.6)$ & $109.5(13.7)^{* * *}$ \\
\hline Immediate memory & $0.48 /($ & 15) & $100.5(13.6)$ & $98.3(11.1)$ & 105. & $108.0(11$. & $99.4(11.9)$ & 101. & $111.1(14.5)^{* * *}$ \\
\hline Visuospatial/con & $1.17 / 0.9$ & $00)$ & $83.4(10.3)$ & $85.5 \quad(8.7)$ & $95.5(20.0)$ & $98.2(14.8)^{* * *}$ & $88.4(16.3)$ & $95.5(20.5)$ & $101.1(14.5)^{* * *}$ \\
\hline Lang & $0.05 /($ & 99) & $01.3(9.7)$ & $96.5 \quad(8.1)$ & $99.6 \quad(7.0)$ & $108.8(8.5)^{* * *}$ & $103.5(8.8)$ & $101.0(8.4)^{*}$ & $105.0(12.6)$ \\
\hline Attent & $0.09 / 0.3$ & 43) & $102.1(15.2)$ & $108.3(20.7)$ & $104.5(16.4)$ & $108.3(15.4)^{*}$ & $112.9(14.0)$ & $105.8(15.7)$ & $106.7(17.7)$ \\
\hline Delayed memory & $1.57 / 1.2$ & 00) & $95.6 \quad(8.2)$ & $95.3(10.1)$ & $100.6(13.1)$ & $107.9(9.9)^{* * *}$ & $93.5(12.2)$ & 99.3 & $110.8(8.8) * * *$ \\
\hline \multicolumn{10}{|l|}{ Trail Making Test } \\
\hline Trails $A^{a}$ & $-0.52 /$ & & $39.9(15.4)$ & $46.5(21.3)$ & $36.0(1$ & $38.5(2)$ & $35.9(10.2)$ & $31.8(15$ & $35.6(27.4)^{* *}$ \\
\hline Trails $\mathrm{B}^{\mathrm{a}}$ & $0.22 / 0.1$ & & $76.8(27.5)$ & $70.8(23.3)$ & 71.7( & $73.4(3$ & $73.3(25.2)$ & 64.1( & $73.3(35.5)$ \\
\hline \multicolumn{10}{|l|}{ Self Report (MASQ) } \\
\hline Total & $0.04 /-0$. & $9(.157)$ & $88.5(18.1)$ & $83.9(13.3)$ & $83.1(16.7)$ & $88.5(14.3)$ & $84.6(11.6)$ & $77.9(15.5)^{*}$ & $87.7(16.2)$ \\
\hline \multicolumn{10}{|l|}{ Self Report (FACT-Cog) ${ }^{b}$} \\
\hline Perceived Cog. Impairments & $0.15 /-$ & 538) & $38.7(17.7)$ & $62.6(16.2)$ & - & $46.7(17.0)^{*}$ & $68.0(12.0)$ & - & $47.6(16.8)^{*}$ \\
\hline Comments From Others ${ }^{\mathrm{a}}$ & $0.16 /-$ & & $12.5 \quad(3.0)$ & $15.5 \quad(1.1)$ & - & $13.4(3.4)$ & $16.0 \quad(0.0)$ & - & $13.0 \quad(3.4)$ \\
\hline Perceived Cognitive Ability & $0.38 /-$ & $(.211)$ & $16.8 \quad(5.8)$ & $25.4 \quad(8.5)$ & - & $20.0(5.9)^{*}$ & $25.8 \quad(8.5)$ & - & $20.1(8.9)^{*}$ \\
\hline Impact on Quality of Life & $-0.24 /-$ & $(.289)$ & $9.6(5.0)$ & $13.4(3.4)$ & - & $9.6(5.1)$ & $14.5 \quad(2.3)$ & - & $11.2 \quad(4.9)$ \\
\hline
\end{tabular}

$* p<.05 \quad * * p<.01 \quad * * * p<.001$ for within-group comparison to $\mathrm{T} 1$

${ }^{\text {a }}$ Non-parametric tests.

${ }^{\mathrm{b}}$ Only 10 intervention participants completed FACT-Cog due to late addition of this measure.

Note. Higher scores indicate better performance for RBANS and FACT-Cog. Lower scores indicate better performance for Trail Making and MASQ. Under Interaction, $\mathrm{d}_{\mathrm{I}-\mathrm{Can}}=$ Effect size for Intervention improvement between $\mathrm{T} 1$ and $\mathrm{T} 2$ corrected for Cancer comparison improvement; $\mathrm{d}_{\mathrm{I}-\mathrm{Com}}=$ Intervention improvement corrected for Community comparison improvement; $p=$ probability value for Group(3) x Time(2) interactions (not applicable for variables requiring non-parametric tests). 
Table 3

Interaction Effects, Means (and Standard Deviations) for Psychosocial Measures

\begin{tabular}{|c|c|c|c|c|c|c|c|c|}
\hline \multirow[t]{3}{*}{ Measure } & \multirow{3}{*}{$\frac{\text { Interaction }}{\mathrm{d}_{\mathrm{I}-\mathrm{Can}} / \mathrm{d}_{\mathrm{I}-\mathrm{Com}}(p)}$} & \multicolumn{3}{|c|}{ Time 1} & \multicolumn{3}{|c|}{ Time 2} & \multirow{3}{*}{$\frac{\text { Time } 3}{\text { Intervention }}$} \\
\hline & & Intervention & Cancer & Community & \multirow[t]{2}{*}{ Intervention } & & \multirow[t]{2}{*}{ Community } & \\
\hline & & & Comparison & & & Comparison & & \\
\hline \multicolumn{9}{|l|}{ Quality of Life (QLQ-C30) } \\
\hline Physical $^{\mathrm{a}}$ & $0.19 / 0.09$ & $87.0(15.0)$ & 90.8 (9.4) & $91.3(18.9)$ & $89.5(12.6)$ & $90.8(11.8)$ & $92.2(13.1)$ & $92.0(13.1)$ \\
\hline Role $^{\mathrm{a}}$ & $-0.05 /-0.05$ & $80.2(26.7)$ & $83.3(19.9)$ & $91.3(24.6)$ & $81.0(21.9)$ & $85.4(18.8)$ & $93.5(17.2)$ & $77.5(29.8)$ \\
\hline Emotional $^{\mathrm{a}}$ & $-0.04 /-0.13$ & $67.9(20.6)$ & $86.5(10.9)$ & $83.0(22.0)$ & $65.1(19.1)$ & $84.4(19.6)$ & $83.0(19.4)$ & $71.7(19.8)$ \\
\hline Cognitive $^{a}$ & $0.15 /-0.07$ & $67.5(21.4)$ & $81.3(16.5)$ & $86.2(17.2)$ & $70.6(15.7)$ & $81.3(18.8)$ & $90.6(13.1)$ & $70.0(23.3)$ \\
\hline Social $^{\mathrm{a}}$ & $0.48 / 0.57$ & $69.8(31.9)$ & $85.4(18.8)$ & $89.1(29.1)$ & $83.3(21.1)^{* *}$ & $85.4(20.8)$ & $84.8(26.5)$ & $78.3(26.5)^{*}$ \\
\hline Global quality of life $\mathrm{e}^{\mathrm{a}}$ & $-0.40 / 0.02$ & $68.7(13.2)$ & $76.0(12.1)$ & $72.5(18.4)$ & $68.7(13.4)$ & $81.3(11.6)$ & $72.1(18.6)$ & $70.8(20.1)$ \\
\hline \multicolumn{9}{|l|}{ Distress (K10) } \\
\hline All participants ${ }^{\mathrm{a}}$ & $0.26 / 0.32$ & $19.4(7.9)$ & $13.5(3.2)$ & $13.2(4.5)$ & $17.5(5.5)$ & $13.3(3.1)$ & $13.4 \quad(4.9)$ & $17.3(6.3)$ \\
\hline Clinical range at $\mathrm{T} 1^{\mathrm{a}}(\geq 20)$ & $-/ 0.85$ & $29.4 \quad(4.7)$ & 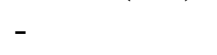 & $23.3(1.5)$ & $22.1 \quad(5.7)^{*}$ & 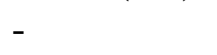 & $19.0 \quad(6.2)$ & $23.0(7.4)^{*}$ \\
\hline \multicolumn{9}{|l|}{ Illness Perceptions (BIPQ) } \\
\hline Consequences & $0.24 /-0.17(.377)$ & $4.0 \quad(3.0)$ & $1.6(1.2)$ & $8.0 \quad(1.5)$ & $3.8 \quad(3.0)$ & $2.0 \quad(1.6)$ & $7.4 \quad(2.5)$ & $3.6 \quad(3.0)$ \\
\hline Timeline $^{\mathrm{a}}$ & $0.22 / 0.36$ & $6.1 \quad(3.5)$ & $5.1 \quad(4.2)$ & $7.9 \quad(1.7)$ & $5.1 \quad(3.4)$ & $5.0 \quad(4.1)$ & $7.9(1.8)$ & $5.4 \quad(3.4)$ \\
\hline Personal cor & $0.24 / 0.23(.814)$ & $4.9 \quad(2.9)$ & $7.1 \quad(1.6)$ & $4.7 \quad(2.2)$ & $5.8 \quad(2.4)$ & $7.4 \quad(2.0)$ & $5.0 \quad(2.3)$ & $6.6(2.2)$ \\
\hline Treatment control $^{\mathrm{a}}$ & $0.40 / 0.04$ & $6.1 \quad(2.8)$ & $5.4 \quad(3.0)$ & $7.4 \quad(2.3)$ & $6.4 \quad(2.9)$ & $4.5 \quad(3.0)$ & $7.6(1.8)$ & $6.8 \quad(2.7)$ \\
\hline Illness identity & $-0.10 / 0.20(.494)$ & $3.9 \quad(3.0)$ & $2.5 \quad(2.4)$ & 6.4 (1.9) & $3.8 \quad(2.7)$ & $2.1 \quad(1.6)$ & 6.8 (1.9) & $3.5 \quad(2.4)$ \\
\hline Concern $^{\mathrm{a}}$ & $0.22 / 0.28$ & $5.6 \quad(3.7)$ & $2.9 \quad(3.0)$ & $8.8 \quad(1.7)$ & $4.9 \quad(3.3)$ & $3.0 \quad(2.9)$ & $8.9 \quad(1.3)$ & $4.5 \quad(3.3)$ \\
\hline Illness coherence & $0.26 / 0.49(.209)$ & $4.8 \quad(3.0)$ & $5.9 \quad(2.9)$ & $6.6 \quad(3.0)$ & $6.7(2.7)^{* *}$ & $7.0 \quad(2.6)$ & $7.0 \quad(2.6)$ & $7.4(2.5)^{* *}$ \\
\hline Emotional representations & $-0.13 / 0.15(.592)$ & $4.8 \quad(3.4)$ & $2.3 \quad(2.1)$ & $8.0 \quad(1.8)$ & $4.9 \quad(3.2)$ & $2.0 \quad(2.6)$ & $8.5 \quad(1.3)$ & $4.2 \quad(3.3)$ \\
\hline
\end{tabular}

$* p<.05 * * p<.01$ for within-group comparison to T1

${ }^{a}$ Non-parametric tests.

Note. Higher scores indicate better quality of life for QLQ-C30 and more functional illness perceptions for personal control, treatment control and illness coherence. Lower scores indicate less psychosocial distress on K10 and more functional illness perceptions for consequences, timeline, illness identity, concern, and emotional representations. Under Interaction, $\mathrm{d}_{\mathrm{I}-\mathrm{Can}}=$ Effect size for Intervention improvement between $\mathrm{T} 1$ and $\mathrm{T} 2$ corrected for Cancer comparison improvement; $\mathrm{d}_{\mathrm{I}-\mathrm{Com}}=$ Intervention improvement corrected for Community comparison improvement; $p=$ probability value for Group(3) x Time(2) interactions (not applicable for variables requiring non-parametric tests). 


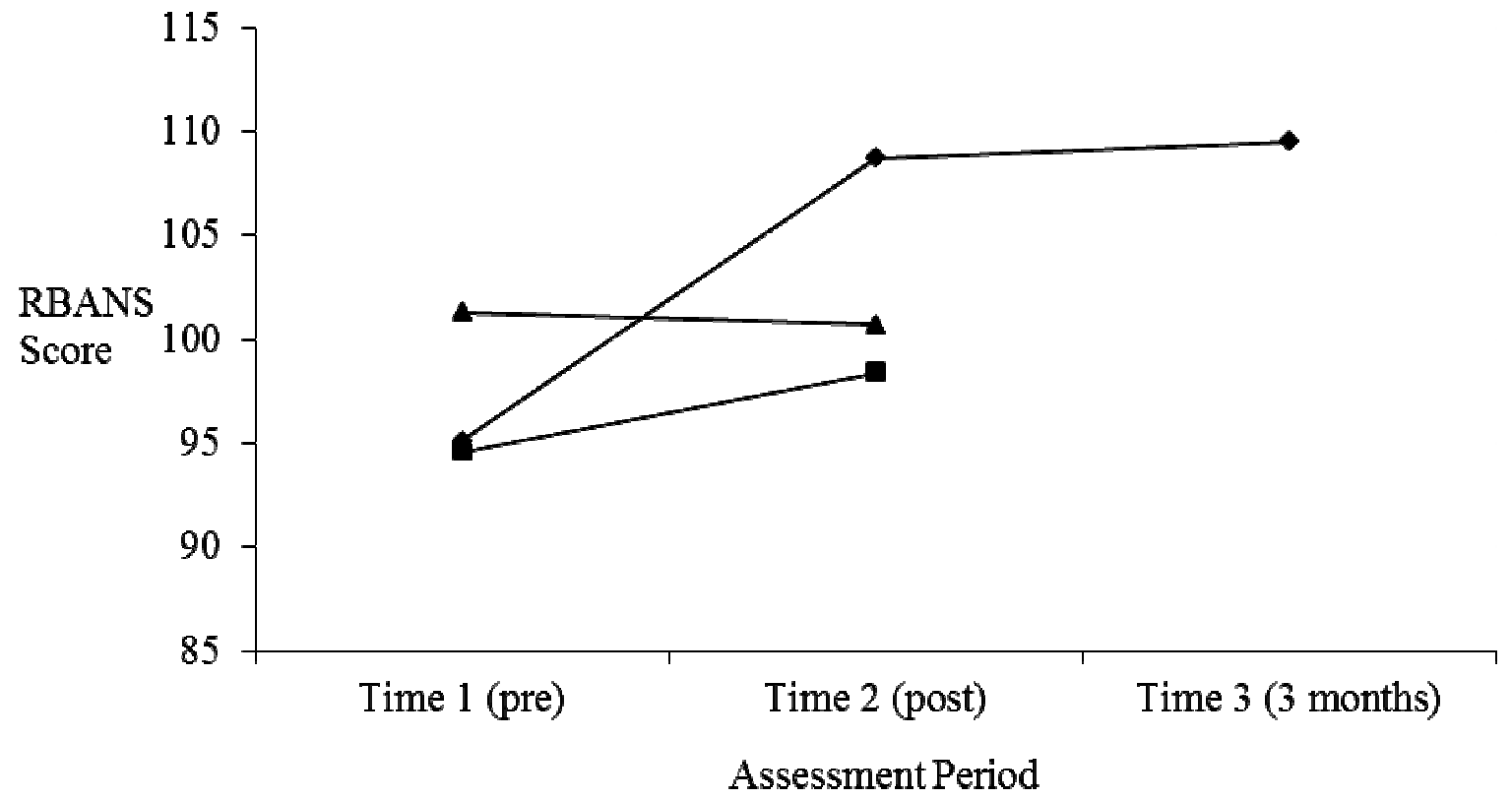

$\rightarrow$ Intervention group $\rightarrow-$ Cancer comparison group $\rightarrow$ Community comparison group

Figure 1. Change in RBANS total score over time for each group. 